\title{
Assessment of Marine Meiobenthic Assemblages in Transplanted Mangrove Forests along the Inner Gulf of Thailand
}

\author{
$\operatorname{AUTHOR}(\mathrm{S})$ :
}

ARYUTHAKA, CHITTIMA; JITTANOON, CHAWAPORN

\section{CITATION:}

ARYUTHAKA, CHITTIMA ...[et al]. Assessment of Marine Meiobenthic Assemblages in

Transplanted Mangrove Forests along the Inner Gulf of Thailand. Publications of the Seto Marine Biological Laboratory. Special Publication Series 2010, 10: 65-74

\section{ISSUE DATE:}

2010

URL:

http://hdl.handle.net/2433/144637

RIGHT: 


\title{
Assessment of Marine Meiobenthic Assemblages in Transplanted Mangrove Forests along the Inner Gulf of Thailand
}

\author{
ChitTima Aryuthaka and Chawaporn JitTANOON
}

\author{
Department of Marine Science Faculty of Fisheries, Kasetsart University \\ Bangkok 10900, Thailand
}

\begin{abstract}
Two transplanted mangrove forests in the Inner Gulf of Thailand were selected for this study. One was on the mud flat in Samut Songkhram Province and another was on sand flat in Phetchaburi Province. There were differences in species and ages of mangroves transplanted in the study sites. Sediment samples were collected randomly for analyses of meiobenthic communities and granulometric properties. Samples were collected from under 7-year old \& 4 - year old Avicennia alba and 4 - year old Sonneratia caseolaris stands in Samut Songkhram site and from 7 - years \& 1- year old Rhizophora apiculata and 7 - year old Avicennia alba stands. Average meiobenthic densities (ind.10 $\mathrm{cm}^{-2}$ ) varied, ranging from $452.62 \pm 23.24-654 \pm 59.42$ in Samut Songkhram and $382.96 \pm 45.38-627.30 \pm 56.89$ in Phetchaburi sites. There were significant differences in their densities among samples. Higher densities occurred in samples under older transplanted tree stands in both sites. Also, within stands of the same age of transplanted trees, meiofaunal average densities were different between mangrove species. In Samut Songkhram site, average density in Avicennia alba samples $(540 \pm 42)$ was higher than that in Sonneratia caseolaris samples (453 \pm 23$)$. Also, this value in Avicennia alba samples (627 \pm 57$)$ was higher than that in Rhizophora apiculata samples $(587 \pm 44)$ in Phetchaburi site. For meiobenthic composition, there were a total of eight taxa recorded, namely nematodes, copepods, polychaetes, oligochaetes, halacarids, tardigrads, kinorynchs and tanaids. According to an average percentage of their total abundances in Samut Songkhram and Phetchaburi mangrove forests, nematodes were the most dominant with values of $92.74 \pm 1.0$ and $93.21 \pm 0.76 \%$, while harpacticoid copepods were second with values of $6.51 \pm 0.47$ and $6.42 \pm 0.69$ in each sites, respectively. Analysis of meiobenthic assemblages using non-parametric multi dimensional scaling showed differences between sampling sites and transplanted mangrove species. Minor meiobenthic taxa, such as oligochaetes, halacarids, tardigrads, kinorynchs and tanaids, also showed significant differences which could be related to habitats, tree species and age of mangrove stand. Results of the present study reveal that meiobenthic assemblages can be used to detect subtle environmental effects and are, therefore, ideal organisms to use to monitor the mangrove recovery.
\end{abstract}

Key words: meiobenthos, marine ecology, mud flat, sand flat

\section{Introduction}

Mangrove is an ecologically and economically important coastal habitats. In Thailand mangrove forests occur on sheltered muddy shores and estuaries of the Gulf of Thailand and Andaman Sea. Between 1961 and 1989, the mangrove forest had been reduced from 356,700 ha, caused by many activities, such as mining, solar salt farms, infrastructure development and a variety of agricultural and urban uses (Flaherty and Karnjanakesorn, 1995). Particularly, due to the success of shrimp fry production, mass culture technique and demand of shrimp production from foreign market, the natural mangrove forest and the coastal area have been intensively developed to shrimp culture farm since 1985. Tookwinas and Ruangpan (1991) stated that shrimp culture ponds accounted for $64 \%$ of the encroached mangrove area from 1986 to 1989. Intensive shrimp culture farms have been expanded rapidly. Many of these farms have proved nonsustainable, with the result that large areas of ponds have been left idle and disused (Stevenson, 1997). Therefore, recently, the transplanted mangrove 
forests have been done extensively by the government offices, NGOs and local communities to restore the environmental conditions within the pond site and the surrounding area. To achieve success in future coastal management and sustainable resources utilization, basic information in transplanted mangrove forests are essential.

Meiobenthos are small invertebrates passing though a $500 \mu \mathrm{m}$ mesh sieve but retained on a 63 $\mu \mathrm{m}$ mesh sieve. They play an important role in nutrient mineralization and as primary consumers of bacteria and algae (Tietjen, 1980). They also are potential food to fish and shrimp larvae (Kahan et al., 1982; Nelson and Coull, 1989). In addition, more attention is paid on meiobenthos because of their potential as a pollution indicator and a key factor for assessment of environmental condition of the coastal habitats because of their high density and diversity, small individual body size, short life cycle and stationary existence (Tietjen and Lee, 1984; Warwick, 1993; Somerfield et al., 2000; Clarke and Warwick, 2001).

The aims of this study are to examine preliminarily the meiobenthic communities and to know their community structure between the different planted mangrove species in the transplanted mangrove forests along a coast of the Gulf of Thailand.

\section{Materials and methods}

\section{Study sites}

The study was carried out in two sites of transplanted mangrove strands along a western coast of the Gulf of Thailand from July 2001 to May 2004. These two sites were at an intertidal mud flat in Ban Klong Klone, Samut Songkhram Province and at an intertidal sand flat in Huai Sai, Phetchaburi Province (PB). The sampling site in Samut Songkhram (SS) was at latitude $13^{\circ} 20^{\prime} \mathrm{N}$ and longitude 99 $58^{\prime}$ 'E (Fig.1a). Various species of mangroves, with two main species of Avicennia alba and Sonneratia caseolaris, have been planted on the mud flat in the seaward fringe of natural mangrove forest with dominance of A. alba since 1997. Besides sampling site in Petchaburi (PB) located at latitude $12^{\circ} 41^{\prime} \mathrm{N}$ and longitude $99^{\circ} 57^{\prime} \mathrm{E}$ (Fig.1b). Two species of mangrove plants, namely Rhizophora apiculata and Avicennia alba, were planted mainly on the sand flat in the sampling area.
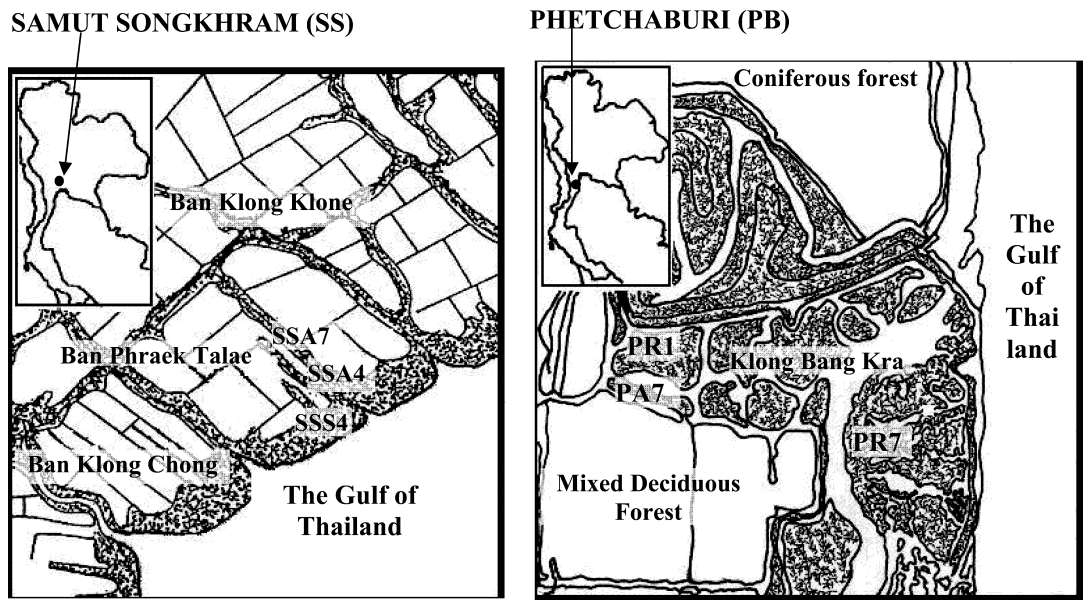

Fig. 1. Map of study sites and sampling area in Samut Songkhram (SSA7, SSA4 \& SSS4) and Phetchaburi (PBA7, PBR7 \& PBR1) sites. 


\section{Field sampling}

Main species and age of mangrove plants were different between both sampling sites. However, Avicennia alba stands were found generally in both sites. To reveal variability both within and between the sites, three areas of different main mangrove stands transplanted were selected independently in each sampling site. Samplings were done in areas of 7-year old \& 4 - year old Avicennia alba (SSA7 \& SSA4) and 4 - year old Sonneratia caseolaris (SSS4) stands in Samut Songkhram site, and in areas of 7 - years \& 1- year old Rhizophora apiculata (PBR7 \& PBR1) and 7 year old Avicennia alba (PBA7) stands in Phetchaburi site. In each sampling areas, four mangrove stands were pointed randomly as four replications in data analyses. Also, to detect variability within each replication, four sediment samples were collected randomly under each stand.

Sediment sample was collected to $10 \mathrm{~cm}$ depth using a plastic tube with cross sectional area of $7.07 \mathrm{~cm}^{-2}$ for faunal analysis. The sediment, preserved with $10 \%$ neutral formalin solution, was kept in plastic bottle and taken to laboratory for faunal extraction processes. Adjacent to the meiofaunal core, two larger corers with cross sectional area of $10 \mathrm{~cm}^{-2}$ were used to collect sediment samples for analyses of granulometric properties and organic content. These sediment samples were kept in plastic bags and moved to dry up under ambient conditions at laboratory.

\section{Laboratory procedures}

Meiobenthos were extracted from the sediment using the protocol of Somerfield and Warwick (1996). The preserved sediment sample was washed through sieves of 500 and $63 \mu \mathrm{m}$ mesh opening to remove sand and clay from the sample. Then, floatation technique in silica colloidal (Ludox $\left.{ }^{\mathrm{TM}}\right)$ with 1.15 of specific gravity was used to extract meiobenthos from fine particles in the residue on a $63 \mu \mathrm{m}$ mesh sieve. The extracted meiobenthos were washed by filtered freshwater through a $63 \mu \mathrm{m}$ mesh sieve. The residue on a $63 \mu \mathrm{m}$ mesh sieve was moved into a mixture of $10 \%$ glycerin and $90 \%$ ethanol solution in plastic bottle. Steps of meiobenthos floatation to preservation were repeated three times to ensure all faunal extracted from the sediment. Each extracted sample was moved into a small glass petri dish and allowed ethanol evaporated for few days to be an anhydrous glycerol. Pure glycerin sample was spread within a frame made of paraffin wax on a microscope slide and covered with a cover slip. The sample slide was examined under a compound microscope. Meiobenthos in each sample slide were identified to taxon level based on pictorial keys of Higgins and Thiel (1988). All individual numbers were counted and expressed as its densities in area of $10 \mathrm{~cm}^{-2}$. For meiobenthic composition, a relative percentage abundance of each taxon was calculated based on its density in each sample.

For granulometric properties, each sediment sample, dried under room ambient conditions, was oven dried at $105^{\circ} \mathrm{C}$ for $24 \mathrm{~h}$ and weighed for $30 \mathrm{~g}$ sample. The sample was subsequently sieved through a series of sieves $(2,1,0.5,0.25,0.125$ and $0.063 \mathrm{~mm})$. Grain size and sediment composition were determined on the basis of the weight of each size fraction (Buchanan, 1984). To estimate an organic content in sediment, the chemical method of Walkley and Black (1934) was used. A $1 \mathrm{~g}$ of oven dried sediment sample was digested with a chromic acid - sulfuric acid mixture. Then the excess of chromic acid, not reduced by the organic matter, was titrated with a standard ferrous salt $\left(\mathrm{FeSO}_{4}\right)$. A content of organic matter was expressed as a relative percentage of that in sediment dried weight.

\section{Data analyses}

Biological data were analyzed using univariate and multivariate techniques. The significant differences in univariate measures between two sites and among different mangrove stands were tested using two - way nested ANOVA. Samples "SSA7, SSA4 and SSS4" and "PBA7, PBR7 and PBR1" were nested entirely within the Samut Songkhram site and the Phetchaburi site. Levene's test was used to assess the equality of variance in different samples. For post hoc multiple comparisons, the Student 
- Newman - Keuls test was done when significant differences among samples were detected $(p<0.05)$. Data on meiobenthic composition were analyzed using nonparametric multivariate techniques contained in the PRIMER (Plymouth Routines In Multivariate Ecological Research) package (Clarke and Warwick, 2001). Intersample similarities were calculated using the coefficient of Bray and Curtis (1957) on non transformed abundance data. Based on the original similarity matrix, group average linkage was used for cluster analysis. Besides ordination was by nonmetric multidimensional scaling (MDS) (Clarke and Green, 1988), which attempted to map samples in two dimensions while retaining the rank similarities between samples in the original similarity matrix. The significance of differences between groups of samples was tested using the randomization/permutation procedure one - way ANOSIM (analysis of similarities) (Clarke, 1993).

\section{Results}

\section{Environmental variables}

For granulometric properties, sediment compositions and median grain size of sediment particles were summarized in Table 1. Percentage of sand and silt - clay contents were calculated for sediment compositions. Fig. 2 showed distinguishable variation of sediment composition between sites and

Table 1. Mean values of granulometric properties and content of organic matter in sediment under 7year old \& 4 - year old Avicennia alba (SSA7 \& SSA4) and 4 - year old Sonneratia caseolaris (SSS4) stands in Samut Songkhram site, and under 7 - year old Avicennia alba (PBA7) and 7 years old \& 1- year old Rhizophora apiculata (PBR7 \& PBR1) stands in Phetchaburi site.

\begin{tabular}{lcccccc}
\hline $\begin{array}{l}\text { Environmental } \\
\text { variables }\end{array}$ & SSA7 & SSA4 & SSS4 & PBA7 & PBR7 & PBR1 \\
\hline \% sand & $9.85 \pm 7.14$ & $7.64 \pm 3.18$ & $10.43 \pm 7.11$ & $84.96 \pm 6.12$ & $86.25 \pm 6.56$ & $91.45 \pm 2.46$ \\
\% silt - clay & $90.15 \pm 7.14$ & $92.36 \pm 3.18$ & $89.57 \pm 7.11$ & $15.04 \pm 6.12$ & $13.75 \pm 6.56$ & $8.55 \pm 2.46$ \\
median grain size $(\mu \mathrm{m})$ & $<63$ & $<63$ & $<63$ & $293.15 \pm 75.96$ & $273.78 \pm 67.82$ & $369.72 \pm 87.81$ \\
$\%$ organic matter & $4.25 \pm 0.53$ & $3.56 \pm 0.24$ & $3.45 \pm 0.32$ & $0.40 \pm 0.24$ & $1.07 \pm 0.43$ & $0.81 \pm 0.46$ \\
\hline
\end{tabular}

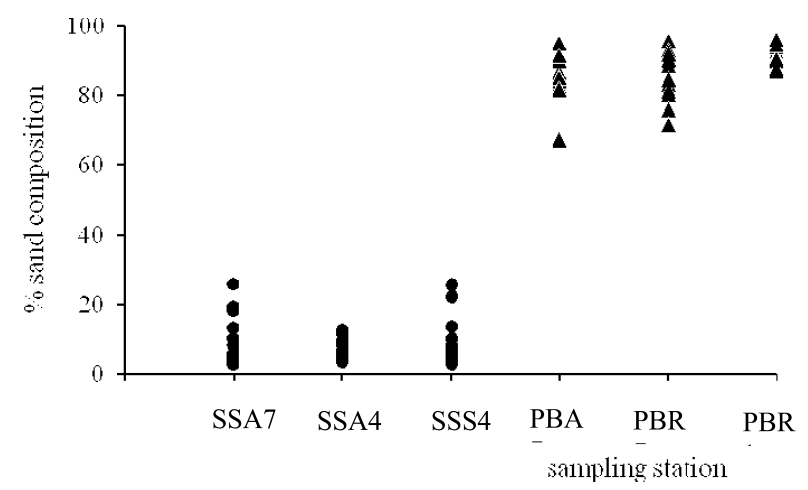

Fig. 2. Variation of percentage of sand composition in sediment samples from under 7-year old \& 4 - year old Avicennia alba (SSA7 \& SSA4) and 4 - year old Sonneratia caseolaris (SSS4) stands in Samut Songkhram site, and under 7 - year old Avicennia alba (PBA7) and 7 - years old \& 1- year old Rhizophora apiculata (PBR7 \& PBR1) stands in Phetchaburi site. 
slightly differences among sediment samples from under different mangrove stands. In Samut Songkhram site, sediment was sandy mud comprising mainly silt - clay contents $(89.57 \pm 7.11 \%$ $92.36 \pm 3.18 \%)$, while it was adversely as muddy sand with very high contents of sand (84.96 \pm $6.12 \%-91.45 \pm 2.46 \%$ ) in Phetchaburi site. Regarding mangrove species, Avicennia alba was transplanted generally in wide range of sediment properties from sandy mud to muddy sand in the study area. Under this mangrove species, median grain size of sediment particles varied widely from less than $63 \mu \mathrm{m}$ to $293.15 \pm 75.96 \mu \mathrm{m}$. For other mangrove species, Sonneratia caseolaris stands were planted in sandy mud with median grain size of less than $63 \mu \mathrm{m}$, whereas sediment particles under Rhizophora apiculata stands were medium sand with range of median grain size from $273.78 \pm$ $67.82 \mu \mathrm{m}$ (PBR7) to $369.72 \pm 87.81 \mu \mathrm{m}$ (PBR1). However it is quite difficult to conclude that granulometric properties related to mangrove species transplanted.

Another important factor in sediment was content of organic matter. In the study, this value was expressed as percentage of organic matter in dried sediment (Table 1). Percent contents of organic matter under mangrove stands were different considerably between two sites but varied slightly among samples in each site (Fig. 3). Between sites, content of organic matter may depend on sediment properties before transplanting mangrove. An average value of this factor in mud samples from Samut SongKhram site $(3.45 \pm 0.32 \%-4.25 \pm 0.53 \%)$ was much higher than that in sand samples from Phetchaburi site $(0.40 \pm 0.24 \%-1.07 \pm 0.43 \%)$. Moreover, there was different pattern in content of organic matter between different age of transplanted mangrove stands. In Samut Songkhram samples, organic matter showed trend of higher content under older mangrove stands. Its value was higher in sediment under 7-year old Avicennia alba stands (4.25 $\pm 0.53 \%)$ than that in sediment under 4 - year old Avicennia alba $(3.56 \pm 0.24 \%)$ and Sonneratia caseolaris stands $(3.45 \pm 0.32 \%)$. Unlikely, there was no such pattern of these values among samples in Phetchaburi site. It showed higher value in samples of 1- year old Rhizophora apiculata stands $(0.81 \pm 0.46 \%)$ than that of 7 - year old Avicennia alba stands $(0.40 \pm 0.24 \%)$. As regards tree species, results showed different content of organic matter deposited in sediment under same species and age of mangrove stands in different sites. The values in samples of 7 - year old Avicennia alba stands varied from $0.40 \pm 0.24 \%$ to $4.25 \pm 0.53 \%$ in Phetchaburi and Samut Songkhram sites.

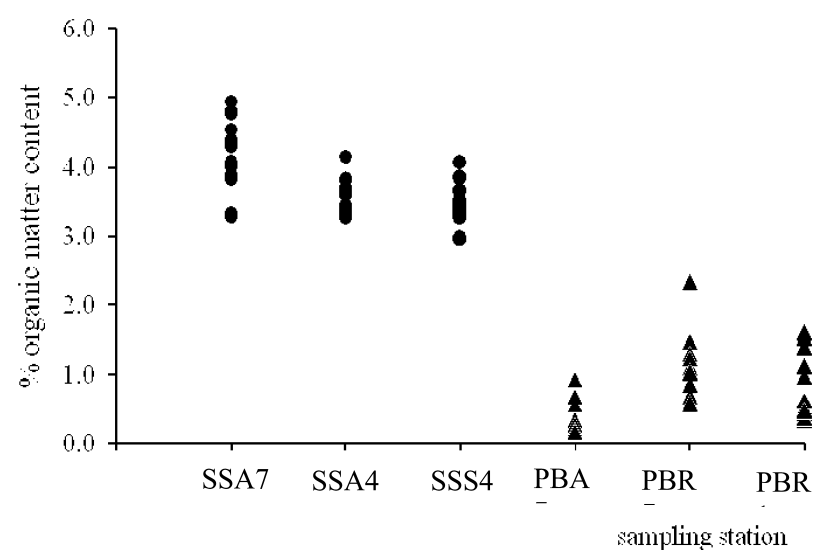

Fig. 3. Variation of percentage of organic matter contents in sediment samples from under 7-year old \& 4 - year old Avicennia alba (SSA7 \& SSA4) and 4 - year old Sonneratia caseolaris (SSS4) stands in Samut Songkhram site, and under 7 - year old Avicennia alba (PBA7) and 7 - years old \& 1- year old Rhizophora apiculata (PBR7 \& PBR1) stands in Phetchaburi site. 


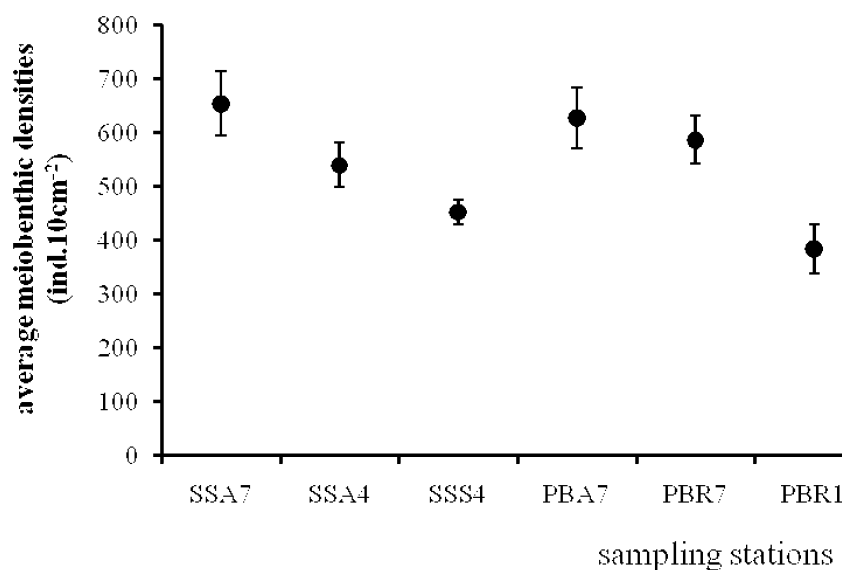

Fig. 4. Average meiobenthic densities (ind.10 $\left.\mathrm{cm}^{-2}\right)$ in Samut Songkhram (SSA7, SSA4 \& SSS4) and Phetchaburi (PBA7, PBR7 \& PBR1) transplanted mangrove forests.

\section{Meiobenthic communities}

Regarding meiobenthic densities, there were no significant differences in their average densities between muddy and sandy sediment sites (Fig. 4). Their average densities (ind.10 $\mathrm{cm}^{-2}$ ) varied, ranging from $452.62 \pm 23.24-654 \pm 59.42$ in Samut Songkhram and $382.96 \pm 45.38-627.30 \pm$ 56.89 in Phetchaburi sites. Results of two - way ANOVA showed no difference between sites but significant differences among samples in each site. Higher densities occurred in samples under older transplanted tree stands in both sites. Also, within stands of the same age of transplanted trees, their average densities were different between mangrove species. In Samut Songkhram site, average density in Avicennia alba samples $(540 \pm 42)$ was higher than that in Sonneratia caseolaris samples $(453 \pm 23)$. Furthermore, this value in Avicennia alba samples $(627 \pm 57)$ was higher than that in Rhizophora apiculata samples $(587 \pm 44)$ in Phetchaburi site. Among all transplanted mangrove species, their average densities showed highest values in the stand of Avicennia alba (627.30 \pm 56.69 - $654.53 \pm 59.42$ ) in both muddy and sandy sediment.

For meiobenthic composition, there were a total of eight taxa recorded, namely nematodes, copepods, polychaetes, oligochaetes, halacarids, tardigrads, kinorynchs and tanaids in the study area. Average densities and percentage of abundance of each taxon were summarized in Table 2. In general, most individuals belonged to two dominant groups: free - living marine nematodes and harpacticoid copepods. The first was the most dominant taxon and it accounted for $92.74 \pm 1.0 \%$ and $93.21 \pm 0.76 \%$ of the total meiobenthic abundance in the Samut Songkhram and Phetchaburi sites. The latter was the second dominant taxon and constituted with range of $6.51 \pm 0.47 \%$ and $6.42 \pm$ $0.69 \%$ in those two sites.

There were slightly differences in numbers of meiobenthic taxa between two sites and also among samples in each site (Table 2). Comparing between sites, sandy habitat seemed to provide more heterogeneity for meiobenthic taxa. So, all eight taxa were found in sandy sediment samples, while only six taxa, excluding oligochaetes and tanaids, occurred in mud samples. Besides, numbers of meiobenthic taxa were different among samples in each site. In Samut Songkhram site, the lowest figure of only 3 taxa was found in 7 - year old Avicennia alba samples, and more numbers of taxa occurred in sediment under younger tree stands. It was unlike that the higher numbers of their taxa were perceived in samples under older tree stands in Phetchaburi site. However, there was no 
Table 2. Average densities (ind $.10 \mathrm{~cm}^{-2} \pm \mathrm{SD}$ ) and abundance percentage of meiofaunal taxa in transplanted mangrove forests in Samut Songkhram and Phetchaburi provinces.

Samut Songkhram site

\begin{tabular}{lcccccc}
\hline \multicolumn{2}{c}{ SSA7 } & \multicolumn{2}{c}{ SSA4 } & \multicolumn{2}{c}{ SSS4 } \\
Taxa & density & $\%$ abund & density & $\%$ abund & density & $\%$ abund \\
\hline Nematodes & $608.20 \pm 55.20$ & $92.92 \pm 0.04$ & $508.13 \pm 43.00$ & $94.07 \pm 0.80$ & $413.01 \pm 23.10$ & $91.24 \pm 0.97$ \\
Copepods & $42.08 \pm 4.22$ & $6.42 \pm 0.07$ & $28.29 \pm 2.00$ & $5.27 \pm 0.61$ & $35.36 \pm 3.06$ & $7.82 \pm 0.73$ \\
Polychaetes & $4.24 \pm 0.00$ & $0.65 \pm 0.06$ & $3.18 \pm 0.71$ & $0.59 \pm 0.14$ & $3.54 \pm 0.82$ & $0.79 \pm 0.21$ \\
Oligochaetes & $0.00 \pm 0.00$ & $0.00 \pm 0.00$ & $0.00 \pm 0.00$ & $0.00 \pm 0.00$ & $0.00 \pm 0.00$ & $0.00 \pm 0.00$ \\
Tardigrads & $0.00 \pm 0.00$ & $0.00 \pm 0.00$ & $0.00 \pm 0.00$ & $0.00 \pm 0.00$ & $0.35 \pm 0.71$ & $0.08 \pm 0.16$ \\
Kinorynchs & $0.00 \pm 0.00$ & $0.00 \pm 0.00$ & $0.35 \pm 0.71$ & $0.07 \pm 0.14$ & $0.00 \pm 0.00$ & $0.00 \pm 0.00$ \\
Halacarids & $0.00 \pm 0.00$ & $0.00 \pm 0.00$ & $0.00 \pm 0.00$ & $0.00 \pm 0.00$ & $0.35 \pm 0.71$ & $0.07 \pm 0.15$ \\
Tanaids & $0.00 \pm 0.00$ & $0.00 \pm 0.00$ & $0.00 \pm 0.00$ & $0.00 \pm 0.00$ & $0.00 \pm 0.00$ & $0.00 \pm 0.00$ \\
\hline Total & $654.53 \pm 59.42$ & $100.00 \pm 0.00$ & $539.96 \pm 41.74$ & $100.00 \pm 0.00$ & $452.62 \pm 23.24$ & $100.00 \pm 0.00$ \\
\hline
\end{tabular}

Phetchaburi site

\begin{tabular}{lcccccc}
\hline & \multicolumn{2}{c}{ PBA7 } & \multicolumn{2}{c}{ PBR7 } & \multicolumn{2}{c}{ PBR1 } \\
Taxa & density & \% abund & density & \% abund & density & $\%$ abund \\
\hline Nematodes & $593.35 \pm 54.40$ & $94.14 \pm 0.48$ & $546.68 \pm 44.62$ & $92.89 \pm 0.92$ & $355.37 \pm 44.69$ & $92.61 \pm 0.88$ \\
Copepods & $32.09 \pm 2.91$ & $5.56 \pm 0.37$ & $37.04 \pm 2.54$ & $6.62 \pm 0.85$ & $26.52 \pm 1.55$ & $7.07 \pm 0.84$ \\
Polychaetes & $0.97 \pm 0.73$ & $0.16 \pm 0.09$ & $1.06 \pm 0.50$ & $0.17 \pm 0.07$ & $0.71 \pm 0.29$ & $0.22 \pm 0.14$ \\
Oligochaetes & $0.53 \pm 0.61$ & $0.08 \pm 0.09$ & $1.06 \pm 0.76$ & $0.19 \pm 0.14$ & $0.18 \pm 0.35$ & $0.05 \pm 0.11$ \\
Tardigrads & $0.00 \pm 0.00$ & $0.00 \pm 0.00$ & $0.09 \pm 0.18$ & $0.01 \pm 0.02$ & $0.09 \pm 0.18$ & $0.03 \pm 0.05$ \\
Kinorynchs & $0.09 \pm 0.18$ & $0.02 \pm 0.04$ & $0.09 \pm 0.18$ & $0.02 \pm 0.04$ & $0.00 \pm 0.00$ & $0.00 \pm 0.00$ \\
Halacarids & $0.18 \pm 0.20$ & $0.02 \pm 0.03$ & $0.44 \pm 0.53$ & $0.07 \pm 0.08$ & $0.09 \pm 0.18$ & $0.02 \pm 0.04$ \\
Tanaids & $0.09 \pm 0.18$ & $0.01 \pm 0.02$ & $0.18 \pm 0.20$ & $0.03 \pm 0.03$ & $0.00 \pm 0.00$ & $0.00 \pm 0.00$ \\
\hline Total & $627.30 \pm 56.69$ & $100.00 \pm 0.00$ & $586.63 \pm 44.12$ & $100.00 \pm 0.00$ & $382.96 \pm 45.38$ & $100.00 \pm 0.00$ \\
\hline
\end{tabular}

Table 3. Results of one - way ANOSIM tests (values of $R$ statistics and significance from permutation tests) for differences in meiobenthic community structure between samples from different sites (SS \& PB), tree species (A, S \& R) and age of mangrove stand (7, $4 \& 1)$.

\begin{tabular}{lccccc}
\hline & $R$ & $P$ & & $R$ & $P$ \\
Global $R$ & 0.750 & 0.001 & & & \\
\hline SSA7 vs SSA4 & 0.667 & 0.029 & SSA4 vs PBR1 & 0.938 & 0.029 \\
SSA7 vs SSS4 & 0.969 & 0.029 & SSS4 vs PBA7 & 1.000 & 0.029 \\
SSA7 vs PBA7 & 0.552 & 0.029 & SSS4 vs PBR7 & 0.938 & 0.029 \\
SSA7 vs PBR7 & 0.729 & 0.029 & SSS4 vs PBR1 & 0.656 & 0.029 \\
SSA7 vs PBR1 & 1.000 & 0.029 & PBA7 vs PBR7 & -0.010 & 0.629 \\
SSA4 vs SSS4 & 0.781 & 0.029 & PBA7 vs PBR1 & 0.958 & 0.029 \\
SSA4 vs PBA7 & 0.583 & 0.029 & PBR7 vs PBR1 & 0.979 & 0.029 \\
SSA4 vs PBR7 & 0.875 & 0.029 & & & \\
\hline
\end{tabular}




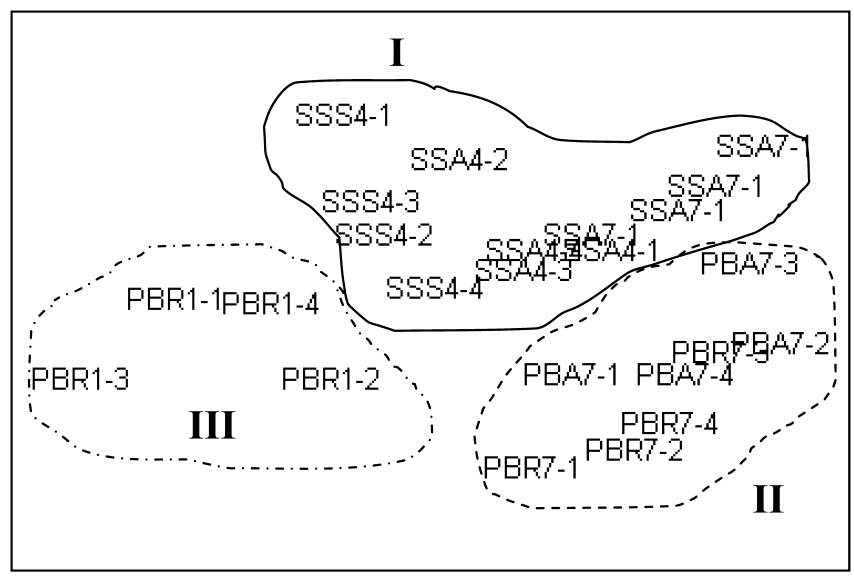

Fig. 5. Multidimensional scaling ordination of meiobenthic community (stree $=0.12$ ) from different tree species $(\mathrm{A}, \mathrm{S} \& \mathrm{R})$ and age of mangrove stand $(7,4 \& 1)$ in two sampling sites (SS \& PB).

consistent pattern of variation in number of meiobenthic taxa among different ages and species of mangrove stands in the study.

Multivariate analyses were performed on the meiobenthic communities at all sampling stations in both study sites. ANOSIM (Table 3) indicates that there was a significant difference between treatments $(P=0.001)$, and also pairwise tests show that the differences between all treatments were significant, except only one (7 - year old Avicennia alba and 7 - year old Rhizophora apiculata) in Phetchaburi site having $P>0.05$. The stress value of 0.12 for the MDS plot indicated a good representation of the sample similarities and there did appear to distinguish three different groups of samples (Fig. 5). Main two groups (I \& II) showed significant differences in meiobenthic communities between muddy and sandy sites. In addition, another group (III) indicated difference in meiobenthic communities under newly planted mangrove stands.

\section{Discussion}

Regarding meiobenthic abundances, there were significant differences in their values among different species and ages of mangrove stands within each site. Therefore, we could not detected clear differences in their abundances between mud flat and sand flat sites. It may imply that mangrove stands transplanted influence on meiobenthic abundances. Results of the present study coincided well with the results of various studies on these groups of fauna in natural mangrove forests along a coast of Thai waters. Previous studies reported there were differences in faunal densities among different mangrove species. In natural Avicennia, Sonneratia and Rhizophora forest at Klong Ngao, Ranong, faunal densities showed variation among samples with different mangrove species (Nozawa, 1983; UNDP/UNESCO, 1991). Nozawa (1983) reported their densities in samples from three main mangrove species stations varied with average values of $953 \pm 612,675 \pm 399$ and $197 \pm 85$ ind.10 $\mathrm{cm}^{-2}$ in Avicennia, Sonneratia and Rhizophora stands samples. In addition, their average densities were 164 - 256 and $70-159$ ind.10 $\mathrm{cm}^{-2}$ in Avicennia and Sonneratia samples (UNDP/UNESCO, 1991). Moreover, Weerawat (2001) reported result of her study on community structure of meiofauna in sediments under four mangrove species, namely Excoecaria, Sonneratia, Rhizophora and Ceriops, stands in Ban ao Makham mangrove forest in Phuket. Their densities in 
sediment under these species stands were $714 \pm 82.8,1,912 \pm 125.5,3,170 \pm 1,109.4$ and $5,459.3 \pm 1,250.2$ ind $.10 \mathrm{~cm}^{-2}$ respectively. Although values of their densities in each mangrove species sample varied among various reports, it seems to be appear trend of highest value in Avicennia samples, followed by values in Rhizophora and Sonneratia samples. Results of the present study coincided well with a trend of meiobenthic densities in natural mangrove forests.

In the study, abundance composition of meiobenthic communities in the transplanted mangrove forests is similar to their composition in the natural mangrove forest in the other locations (e.g. Vietnam (Xuan et al., 2007), Thailand (UNDP/UNESCO, 1991; Paphavasit et al., Aryuthaka, 2001), Malaysia (Somerfield et al.,1998), Kenya (Vanhove et al., 1992), South Africa (Dye, 1983)). Free living marine nematodes dominated the meiobenthos and harpacticoid copepods came in second at all sampling stations in both mud and sand flat sites in the study. So, the usage of a nematode/copepod ratio (N/C ratio), proposed by Raffaelli and Mason (1981), was not effective to detect differences in their community structures among different environments and by impact of environmental changes. However, results of multivariate analyses on the meiobenthic communities showed significant differences in meiobenthic communities among different treatment. Such data information and statistical technique seem to be useful mean of environmental assessment in coastal habitats. More studies on community structures of meiobenthos, particularly dominant taxon as free - living marine nematodes are essential for coastal sustainable management.

\section{Acknowledgments}

We would like to express our sincere thanks to staff and students of the Department of Marine Science, Faculty of Fisheries, Kasetsart University, for their assistances and encouragements. Many thanks go to Mr. Hiromu Ikenoue for his helpful comments.

\section{References}

Aryuthaka, C. 2001. Marine benthic community in the shrimp culture ponds in Thailand. Proceedings of the JSPS NRCT International Symposium on Sustainable Shrimp Culture and Health Management Diseases and Environment. Tokyo University of Fisheries, Japan. Pp. 123-140.

Bray, J. R. and Curtis, J. T. 1957. An ordination of the upland forest communities of southern Wisconsin. Ecological Monograph, 27, 325-349.

Buchanan, J. B. 1984. Sediment analysis. In, Holme, N. A. and McIntyre, A. D. (eds.) Methods for the Study of Marine Benthos, $2^{\text {nd }}$ edition. Blackwell Scientific Publications, Oxford. pp. 41-65.

Clarke, K. R. 1993. Non-parametric multivariate analyses of changes in community structure. Australian Journal of Ecology, 18, 117-143.

Clarke, K. R. and Green, R. H. 1988. Statistical design and analysis of a 'biological effects' study. Marine Ecology Progress Series, 46, 213-226.

Clarke, K. R. and Warwick, R. M. 2001. Changes in Marine Communities: An Approach to Statistical Analysis and Interpretation, $2^{\text {nd }}$ edition. Plymouth Marine Laboratory, Plymouth.

Dye, A.H. 1983. Composition and seasonal fluctuations of meiofauna in a Southern African mangrove estuary. Marine Biology, 73, 165-170.

Higgins, R. P. and Thiel, H. 1988. Introduction to the Study of Meiofauna. Smithsonian Institution Press, Washington D.C. 488 pp.

Flaherty, M. and Karnjanakesorn, C. 1995. Marine shrimp aquaculture and natural resource degradation in Thailand. Environmental Management, 19, 27-37.

Kahan, D., Uhlig, G., Schwenzer, D. and Horowitz, L. 1982. A simple method for cultivating harpacticoid copepods and offering them to fish larvae. Aquaculture, 26, 303-310.

Nelson, A. L. and Coull, B. C. 1989. Selection of meiobenthic prey by juvenile spot (Pisces) : an experiment study. Marine Ecology Progress Series, 53, 51-57.

Nozawa, K., Yoshikawa, N., Shokita, S. and Limsakul, S. 1983. Mangrove meiofauna in Thailand. In : Nozawa, K. (ed.), Mangrove Ecology in Thailand. Report of Thai - Japanese Cooperative Research Project on Mangrove 
Productivity and Development, 1981-1982. The Japanese Ministry of Education, Science and Culture, Tokyo. Pp. 63-72.

Ólafsson, E., Carlström, S. and Ndaro, S. G. 2000. Meiobenthos of hypersaline tropical mangrove sediment in relation to spring tide inundation. Hydrobiologia, 426, 57-64

Paphavasit, N., Dheerapongpaiboon, S., Jivalak, J. and Piumsomboon, A. 1997. Preliminary report on meiofauna community in Samut Songkham mangrove swamp, Thailand. In, Nisihira, M. (ed.), Benthic Communities and Biodiversity in Thai Mangrove Swamps. Biological Institute, Tohoku University. pp. 159-170.

Raffaelli, D. G. and Mason, C. F. 1981. Pollution monitoring with meiofauna using the ratio nematodes to copepods. Marine Pollution Bulletin,12, 158-163.

Somerfield, P. J. and Warwick, R. M. 1996. Meiofauna in Marine Pollution Monitoring Programmes: A Laboratory Manual. Ministry of Agriculture, Fisheries and Food Directorate of Fisheries Research, Lowestoft. $71 \mathrm{pp}$.

Somerfield, P. J., Gee, M. and Aryuthaka, C.,1998. Meiofaunal communities in a Malaysian mangrove forest. Journal of the Marine Biological Association of the United Kingdom, 78, 717-732.

Somerfield, P. J., Yodnarasri, S. and Aryuthaka, C. 2000. The effects of green mussel Perna viridis (L.) (Mollusca: Mytilidae) culture on nematode community structure in the Gulf of Thailand. Raffles Bulletin of Zoology, 48, 263-272.

Stevenson, N. J. 1997. Disused shrimp ponds: options for redevelopment of mangroves. Coastal Management, 25, 425-435.

Tietjen, J. H. 1980. Microbial - meiofauna interrelationships: a review. Microbiology, 1980, 335-338.

Tietjen, J. H. and Lee, J. J. 1984. The use of free - living nematodes as bioassay for estuarine sediments. Marine Environmental Research, 11, 233-251.

Tookwinas, S. and Ruangpan, L. 1991. Marine shrimp and mangrove. Thai Fisheries Gazette, 45, 953-966.

UNDP/UNESCO. 1991. Final report of the integrated multidisciplinary survey and research programme of the Ranong mangrove ecosystems, fauna and fisheries studies. UNDP/UNESCO Regional Mangrove Project RAS/86/120. pp. 82-154.

Vanhove, S., Vincx, M., Van Gansbeke, D., Gijselinck, W. and Schram, D. 1992. The meiobenthos of five mangrove vegetation types in Gazi Bay, Kenya. Hydrobiologia, 247, 99-108.

Walkley, A. and Black, I. A. 1934. An examination of Degtjareff method for determining soil organic matter and a proposed modification of the chromic acid titration method. Soil Science, 37, 29-37.

Warwick, R. 1993. Environmental impact studies on marine communities: pragmatical considerations. Australian Journal of Ecology, 18, 63-80.

Weerawat, P. 2001. Community structure of meiofauna at different mangrove vegetation types at Ban - ao Makham, Phuket Island, Thailand. Master Thesis. Ernational Course Program in Master of Science in Ecological Marine Management (ECOMAMA), University of Ghent. 111 pp.

Xuan, Q. N., Vanreusel, A., Thanh, N.V. and Smol, N. 2007. Biodiversity of meiofauna in the intertidal Khe Nhan mudflat, Can Gio mangrove forest, Vietnam with special emphasis on free living nematodes. Ocean Science Journal, 42, 135-152. 